\title{
Calcium-Channel-Blocker-Influenced Gingival Enlargement: A Conundrum Demystified
}

\author{
Pallavi Tonsekar ${ }^{1, *}$ and Vidya Tonsekar ${ }^{2}$ \\ 1 Private Practice, Falls Church, VA 22042, USA \\ 2 Private Practice, Mumbai 400059, India; vtonsekar@gmail.com \\ * Correspondence: pallavitonsekar@gmail.com
}

check for updates

Citation: Tonsekar, P.; Tonsekar, V. Calcium-Channel-Blocker-Influenced Gingival Enlargement: A Conundrum Demystified. Oral 2021, 1, 236-249. https://doi.org/10.3390/ oral1030023

Academic Editor: Eugenio Pedullà

Received: 15 May 2021

Accepted: 28 July 2021

Published: 11 August 2021

Publisher's Note: MDPI stays neutral with regard to jurisdictional claims in published maps and institutional affiliations.

Copyright: (c) 2021 by the authors. Licensee MDPI, Basel, Switzerland. This article is an open access article distributed under the terms and conditions of the Creative Commons Attribution (CC BY) license (https:/ / creativecommons.org/licenses/by/ $4.0 /)$.

\begin{abstract}
The aim of the article is to discuss the development of calcium channel blocker (CCB) influenced gingival enlargement. Data and Sources: MEDLINE/PubMed, Scopus, ScienceDirect, and Google Search databases. The article reviews contemporary and classic literature with a focus on pathophysiology, clinical presentation, and risk factors associated with this condition. The application of various treatment options is also discussed. Study selection: Clinical studies, systematic reviews, in vitro studies, and case reports. Conclusion: Dental plaque, genetic predisposition, and type of drug used are critical in the development of drug-influenced gingival enlargement (DIGE). The surgical technique employed to treat the pathosis plays an important role in long term success of therapy. There has been an upward trend in occurrence of CCB-influenced gingival enlargement due to the unbridled use of CCBs. Due to the cosmetic and functional ramifications; the review underscores the importance of clinical research on prevention, treatment, and causes of recurrence of CCB-influenced gingival enlargement.
\end{abstract}

Keywords: drug-influenced gingival enlargement; calcium channel blockers; adverse drug reactions; side effect; nifedipine; amlodipine

\section{Introduction}

Drug-influenced gingival enlargement (DIGE) is overgrowth of gingival tissue as a side effect associated with use of systemic medication [1]. Currently, more than 35 prescription medications have been implicated to cause gingival enlargement [1-3] (Table 1). Out of these, calcium channel blockers (CCBs) are some of the most common causative agents of DIGE. CCBs act by binding to and blocking the L-type calcium channels found in myocardial and vascular smooth muscles [4]. Since muscle contraction is dependent on extracellular calcium influx into the myocyte, this inhibition of calcium flow causes arterial vasodilation and decreased peripheral resistance, resulting in reduced blood pressure, decrease in myocardial force (negative inotropic effect), heart rate (negative chronotropic effect), and flow velocity within the heart (negative dromotropic effect) [4]. Based on their chemical structure and effects on smooth muscle, they are classified into three groups: dihydropyridines (e.g., nifedipine, amlodipine, isradipine) are powerful vasodilators; phenylalkylamines (e.g., verapamil) are potent myocardial depressants; and benzothiazopines (e.g., diltiazem) are moderate vasodilators and myocardial depressants [4]. CCBs are also categorized based on formula and duration of action [5]. Nifedipine, verapamil, and diltiazemare short-acting, first-generation CCBs; manidipine and nicardipine are second-generation CCBs and have longer duration of action; amlodipine and isradipine are third-generation CCBs and are long-acting drugs whose prolonged action is due to sustained blood concentrations and long half-life [5]. Newer-generation CCBs were created due to the strong side effects of first-generation CCBs, such as tachycardia, headaches, and peripheral edema [5]. However, CCBs across generations have been associated with gingival enlargement (GE) [1,2]. CCB-influenced gingival enlargement occurs when the periodontium becomes an unintended target of the drug. The development, clinical, and 
histological presentation is very similar to GE caused by other drugs. Nonetheless, it is attributed with some unique features. The literature on CCB-influenced gingival enlargements conflicting and at times, confusing. The aim of the present review is to elucidate its pathogenesis and treatment.

Table 1. Drugs that are documented to cause Gingival Enlargement.

\begin{tabular}{cc}
\hline CALCIUM CHANNEL BLOCKERS & $\begin{array}{c}\text { Amlodipine, Benidipine, Diltiazem, Felodipine, } \\
\text { Manidipine Nitrendipine, Nicardipine, Nifedipine, } \\
\text { Nisoldipine, Nimodipine, Verapamil }\end{array}$ \\
\hline ANTI-EPILEPTIC DRUGS & $\begin{array}{c}\text { Carbamezepine, Clobazam, Diazepam, } \\
\text { Ethosuximide, Ethotoin, Gabapentin, Lamotrigine, } \\
\text { Levitiracetam, Methosuxinimide, Mepenytoin, } \\
\text { Phenytoin, Phenobarbitone, Primidone, Sodium } \\
\text { Valproate *, Topiramate, Vigabatrin, Zonisamide }\end{array}$ \\
\hline IMMUNOSUPPRESSIVE DRUGS & $\begin{array}{c}\text { Cyclosporine, Everolimus, Mycophenolate mofetil, } \\
\text { Sirolimus, Tacrolimus }\end{array}$ \\
\hline MISCELLANEOUS & $\begin{array}{c}\text { Erythromycin *, Ethinyl Estradiol, and Lynestrenol } \\
\text { (oral contraceptives, in high doses), Lisinopril * } \\
\text { * Atenolol *, Propanolol * }\end{array}$ \\
\hline Not well documented. &
\end{tabular}

\section{Prevalence}

DIGE was first reported as far back as 1939 by Kimball, who described the condition in patients using phenytoin for epilepsy [6]. Drugs that cause GE are mainly grouped as anti-epileptic drugs, immunosuppressive drugs, and CCBs, although drugs such as oral contraceptives and erythromycin have also been implicated [1-3]. The prevalence of DIGE reported in literature is wide and varied. The prevalence of DIGE ranges between 3-20\% of GE cases [7]. The prevalence of DIGE among patients using the three types of drugs is $90 \%$ [8]. The prevalence of phenytoin-influenced GE is about 10-83\% among patients using phenytoin [9], cyclosporine-influenced GE is $25-30 \%$ among patients using cyclosporine [2], and CCB-influenced GE is about $30-50 \%$ in CCB users [9]. Gingival enlargement associated with nifedipine (NIGE) was first reported in 1984 [10,11]. Amlodipine-influenced gingival enlargement (AIGE) was first reported in 1994 by Seymour et al. [12]. Among CCBs, nifedipine appears to have the highest prevalence rate of 6-15\% [13] The prevalence of GE is $5-20 \%$ in patients taking diltiazem, $5 \%$ in users of verapamil, and $3.3 \%$ in patients taking amlodipine, although due to the surge in long-term use for hypertension and angina, the prevalence in patients taking amlodipine has been reported to be as high as $26.7 \%$ [13]. An increased incidence of CCB-influenced DIGE has been associated with concurrent medications, such as cyclosporine [14-16], phenytoin [7], and statins [17]. Diltiazem, nicardipine, nitrendipine, manidipine [1-3], and felodipine [18] are also associated with GE. Table 1 enumerates the drugs that have been reported to cause GE.

\section{Pathophysiology}

At the cellular level, drugs across genres associated with GE appear to have a similar mechanism of action [1,9]. Brown et al. presented a hypothesis that consolidates previous theories on the pathogenesis of DIGE [9]. These drugs have an inhibitory effect on sodium/calcium cation channels $(\mathrm{Na} / \mathrm{Ca}++)$, which results in blockage of influx of calcium ions into fibroblasts [9]. Due to regulatory effect of calcium channels on folate (FA) uptake, this results in reduced uptake of FA into fibroblasts [9]. This in turn causes a decline in e-cathedrin, a calcium-dependent gene molecule crucial for epithelial cell to cell adhesion, and SMAD (Small Mothers Against Decapentaplegic) gene, a transducer-signaling protein for transforming growth factor-beta 1 (TGF beta1) [9]. The TGF-beta family of growth factors regulates cell development and proliferation via an incredibly complex system of cross-talking signaling pathways of which the SMAD pathway appears to play a key role 
in DIGO through its action on tissue inhibitor of metalloproteinase-1 (TIMP-1) and matrix metalloproteinases (MMPs) [9]. Interleukin-6 (IL6), a pleotropic cytokine, also acts on TIMP-1 [8]. There is a resultant increase in TIMP-1 and a decrease in MMP-1 [8,9], which is required to activate collagenase. The reduced collagenase activity results in decreased collagen breakdown, and accumulation of collagen and other extra cellular matrix (ECM) content occurs as a consequence. In addition, nifedipine has been demonstrated to cause an increased synthesis of keratinocyte growth factor (KGF) by fibroblasts in vitro [9]. KGF is known to regulate epithelial growth by stimulating cell mitosis and reducing apoptosis of epithelial cells [9,13]. Increased synthesis of B-cell lymphoma 2 (BC12) oncoprotein, which inhibits apoptosis of keratinocytes, has also been found in amlodipine-associated GO [9]. It is also important to remember that gingiva is a target tissue for androgen metabolism and contains receptors for 5-alpha-dihidrotestosterone (DHT). Nyska et al. proposed a mechanism by which CCB-influenced GO developed in a canine model [19]. CCBs block aldosterone synthesis due to their calcium flux inhibiting properties, which creates a feedback increase in pituitary ACTH secretion [19]. This causes adrenal gland hyperplasia and increased synthesis of steroids, such as pregnenolone [19]. There is a resultant increase in production of testosterone, an anabolic steroid that causes proliferation of fibroblasts and collagen via DHT receptors [19]. Sooryamurthy et al. similarly reported exaggerated DHT production from testosterone by gingival fibroblasts in patients with GE who were on nifedipine and/or cyclosporine [20]. Figure 1 shows the possible mechanisms of CCB influenced gingival overgrowth.

FIGURE 1: POSSIBLE MECHANISMS OF CCB - INFLUENCED GINGIVAL ENLARGEMENT

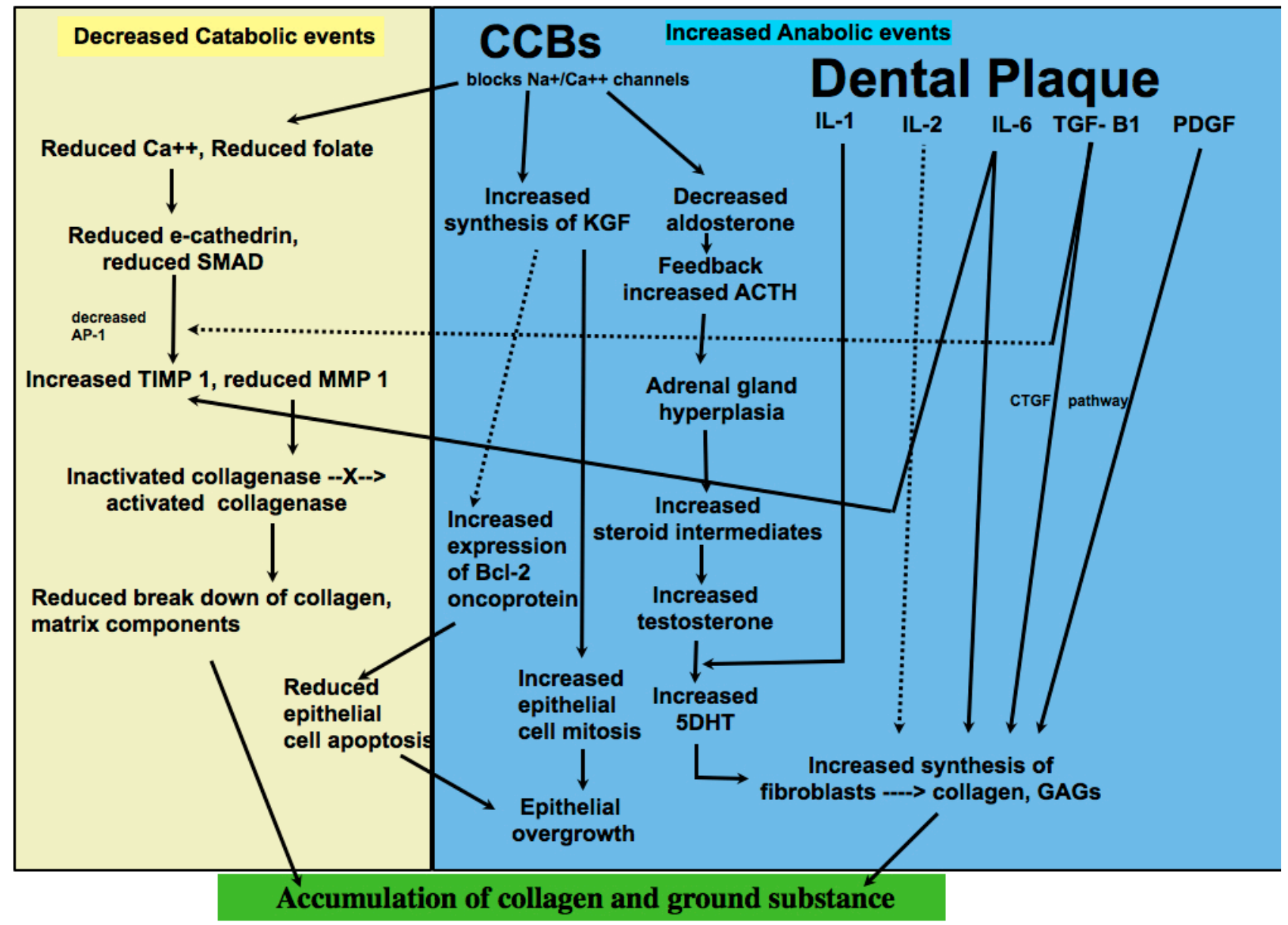

Figure 1. Cont. 


\section{KEY FOR FIGURE 1:}

- CCB-Calcium Channel Blockers

- $\mathrm{Na}+/ \mathrm{Ca}++-$ Sodium/calcium cation channels

- SMAD- Small Mothers Against Decapentaplegic family of proteins

- TIMP- Tissue Inhibitor of Metalloproteinases

- MMP- Matrix Metalloproteinases

- KGF- Keratinocyte Growth Factor

- $\quad$ ACTH-Adrenocorticotropic Hormone 5 DHT -Dihydrotestosterone, a product of Testosterone

- GAGs- Glycosaminoglycans

- IL-Interleukins

- TGF B1-Transforming Growth Factor Beta-1

- $\quad$ PDGF- Platelet Derived Growth Factor

- CTGF- Connective Tissue Growth Factor

- Dotted Lines- Not well documented but possible mechanisms

- Dotted Line with $\mathbf{X}$ (cross)- Prevent activation to collagenase

- $\quad$ AP-1 Activator Protein that inhibits TIMP

Figure 1. Possible mechanisms of CCB influenced gingival overgrowth.

A plethora of studies have shown that presence of dental plaque is critical in the development and manifestation of DIGE $[1,7,9,13,21]$. Bacterial plaque in gingival crevicular fluid (GCF) causes an increase in synthesis of both pro inflammatory cytokines, such as interleukins IL-1 [1], IL-2 [21], 1L-6 [8], and anti-inflammatory cytokines and mitogens, such as TGF-beta 1 [22], platelet-derived growth factor (PDGF), and insulin-like growth factor (IGF) [23]. It has been proposed that stimulation of gingival fibroblasts occurs when they are exposed to CCBs and pro-inflammatory cytokines, such as IL-1 [1,8]. Kasasa et al. reported that IL-1 caused an increase in production of 5DHT from labelled testosterone in human gingiva and periodontal ligament (PDL) [24]. In addition, increased expression of IL6 has been found in cyclosporin-, phenytoin-, and nifedipine-influenced GE [8]. IL-6, which has pro- as well as anti-inflammatory tendencies, causes an increase in fibroblast proliferation and glycosaminoglycans synthesis by targeting fibroblasts and accumulation of connective tissue (CT) components by increasing TIMP-1 synthesis [8]. Growth factors, such as TGF-beta, connective tissue growth factor (CTGF), and PDGF, regulate fibroblast proliferation and collagen synthesis and reduce cell apoptosis [25]. Taken together, DIGE appears to be a result of an imbalance between anabolic and catabolic events, and the cumulative effect is accumulation of gingival collagen and ground substance. There is conflicting evidence on whether CCBs have a direct or indirect effect on gingival fibroblasts. Nishikawa et al. demonstrated in an in vitro study that in lower doses, nifedipine did not have any effect on fibroblast growth and proliferation [21]. They concluded that the effect of nifedipine is indirect, as the presence of local inflammatory factors is necessary for nifedipine to stimulate cytokine and/or DHT production by gingival fibroblasts, resulting in increased collagen synthesis. [21]. On the other hand, it has been theorized that inflammation may develop as a result of direct effects of the drug in gingival crevicular fluid (GCF) [9].

\section{Effect of Dose on Pathogenesis}

The dose of the drug is considered to be an important factor in the development and severity of DIGE by some authors who noted that the severity of the condition was directly 
related to the dose $[7,13]$, while others have disproved the theory due to presence of the condition even in some patients who were taking relatively lower doses [26,27].

It has been shown that GE occurs when nifedipine is taken at a dose of $5 \mathrm{mg} /$ day, $10 \mathrm{mg} /$ day, or $20-40 \mathrm{mg} /$ day $[7,21,22,28]$. The condition is either noticed or treated about 2-18 months after medication is started [21]. Amlodipine has been associated with GE even in doses as low as $2.5 \mathrm{mg} /$ day taken over a longer duration of time [13]. Khzam et al. reported a case of DIGE that occurred within a few days after use of felodipine $400 \mathrm{mg}$ for hypertension [18]. Ikawa reported a case where gingival enlargement was seen in a patient taking manidipine at a dose of $20 \mathrm{mg}$ /day for several months before surgical intervention [29]. The range of dose and time of occurrence may be attributed to factors such as the drug used, oral hygiene habits, concurrent use of medication, such as statins, and other existing diseases, such as diabetes mellitus. The appearance of DIGE even in low doses should be factored in while determining the possibility of drug modulation as the initial course of treatment.

\section{Clinical Features}

The clinical presentation of GE is similar among various drugs [7]. In general, DIGE is observed at an average of three months after commencement of the drug regime [30]. The condition usually begins as a nodule in the interdental papilla, which gradually enlarges, involving the facial and palatal/lingual margins [1]. The interdental papillae eventually coalesce with the enlarged gingival margins and may result in a massive tissue fold over the tooth surfaces, impeding masticatory function and/or speech [1]. It may extend to the crowns, causing extensive disfigurement of gingiva [28]. The gingival enlargement in the early stages appears to be painless; however, in more advanced cases, it can cause considerable discomfort during mastication. A feeling of heaviness has been reported in severe cases [28].

DIGO is described as a diffuse, generalized swelling affecting anterior, posterior, labial, and lingual surfaces of maxilla and mandibular gingiva [12]. Typically, it is more severe in the maxillary and mandibular anterior facial/labial surfaces [28].

The clinical observation that DIGO usually begins in the interdental papillae can be explained by the theory that the interdental papillae provide a more suitable nidus for GO to develop [25]. This may be due to the greater expression of CTGF and integrins in papillary epithelium, which are important for regulating fibroblast synthesis of collagen and GAGs [25].

When plaque-induced gingival inflammation is not superimposed with DIGE, the lesion has been described as a pink, mulberry shaped, fibrotic-lobulated mass, which is often pedunculated $[1,7,28]$. In severe cases, when the enlargement extends to attached gingiva, a loss of scalloping is observed [28]. Lafzi et al. described the lesion to be an outward advancement of gingival tissue rather than a vertical one in that the mean probing depth was only $2.4 \mathrm{~mm}$ [31]. Typically, however, the condition is described to cause 'pseudo' pockets due to enlargement of gingiva from beneath the gingival margin with an increase in the probing depths and little or no clinical attachment loss [30].

In the presence of inflammation, gingival tissue appears edematous, soft, and fluctuant. Newman et al. noted that these secondary inflammatory changes cause an increase in the size of the gingiva, which appears to have a bluish or reddish tinge [32]. Ikawa et al. described the lesion as being shiny and erythematous in areas where greater excrement of dental plaque was observed [29]. Spontaneous gingival bleeding and bleeding on probing is present [1]. Difficulty in mastication leads to further development of pseudo pockets, bacterial in-growth, and calculus excrements. This is more pronounced in the mandibular anterior region due to greater accumulation of plaque and calculus [28]. Uninhibited bacterial plaque may further cause clinical attachment loss and vertical and horizontal bone loss [7,28,29]. In advanced cases, mobility of teeth [7] is observed, possibly due to clinical attachment loss. Purulent discharge from the gingival crevices may sometimes be detected $[7,29]$. 
The 2017 World Workshop defined DIGE by its extent and severity as localized if it involves one tooth or a group of teeth, generalized if it involves most or all the teeth, mild if it involves only the papilla, moderate if it involves the papilla and margin, and severe if it involves the attached gingiva as well [33].

To define the extent and degree of severity of phenytoin-induced GE, Seymour et al. (1985) devised an index which has been used to define various DIGE in clinical studies [34]. They designated vertical and horizontal (i.e., labio-lingual) components to the labial and lingual gingiva; the vertical component of which can be categorized as (0) no enlargement of interdental papilla on to tooth surface, (1) mild enlargement resulting in a blunted papilla, (2) moderate enlargement involving lateral spread of interdental papilla onto the tooth surface of up to a quarter of tooth width, and (3) marked encroachment of papilla over greater than a quarter of tooth width [34]; and the horizontal component as (0) normal thickness of gingival margin, (1) mild increase in thickness less than $2 \mathrm{~mm}$ from the normal, and (3) marked increase in thickness greater than $2 \mathrm{~mm}$ from the normal [34]. The Seymour index is an indirect and partial mouth index, as study models are used for assessment, and six maxillary and six mandibular anterior teeth are selected for measurement. Hence, there are 20 gingival units in total that are measured in each patient. The sum of vertical and horizontal components provides the score for each gingival unit, which can be a maximum of 5 [34]. The sum of the scores for each gingival unit provides the overall score, a maximum of which can be 100, and therefore can be expressed as a percentage [34]. A GO score of $30 \%$ or greater is considered clinically significant GE requiring surgical intervention [34]. Various methods have been used to define the extent of severity of GE, some using photographic analysis [35], laser scanners [27], and histopathological analysis [1,7]. The reliability, reproducibility, subjectivity, and validity of GE indices have rarely been studied $[27,35]$ and merit further analysis.

CCB-influenced gingival enlargement is sometimes seen in relation to implants [36], edentulous areas [37], and deciduous teeth [38]. A common feature of all DIGE is that it regresses following extraction of teeth in the area [1].

\section{Histopathology and Microbiology}

The histopathology amongst various DIGE is very similar and can be differentiated from normal gingival tissue [1]. In general, it is characterized by acanthotic, stratified squamous epithelium with parakeratosis [31] and irregular, proliferating, elongated rete pegs $[6,21,22]$.

Aldemir et al. observed a fusion in the rete pegs in their report on AIGE [22]. The underlying connective tissue consists of increased number of collagen fibers [21] and ground substance containing a mixture of dense and loose fibers [7,39]. Spindle-shaped gingival fibroblasts are plump and abundant, containing sulfated mucopolysaccharides, considered to be secretory granules of inactive MMPs that form a network [7]. The vascularization is increased and blood vessels appear dilated due to the effect of CCB on the vascular walls $[1,10]$. Perivascular chronic inflammatory cell infiltration consisting of plasma cells and lymphocytes is often present [7]. In a case of manidipine-influenced GE, Ikawa et al. described an increase in round cell infiltrate and edema [29]. NIGE is histologically similar to phenytoin-associated GE due to the presence of dense connective tissue and less inflammatory infiltrate [21]. NIGE may be distinguished from cyclosporine-associated GE on the basis of greater collagen volume, intact elastic fibers, and presence of fibronectins [21]. Khzam et al. reported fibrous epulis and isolated areas of osseous metaplasia surrounded by heavy chronic cell infiltrate in felodipine-influenced GE, which they attributed to preexisting chronic periodontitis [18]. Sanjeev et al. described the presence of calcified areas in the stromal tissue in amlodipine-influenced GE [39]. In a patient who was on amlodipine for hypertension and acute angina and presented with GE, Pasupuleti et al. detected Aggregatibacter actinomycetemcomitans, Porphyromonas gingivalis, and Prevotella intermedia in areas with greater probing depths [7]. A reduction in ECM and inflammatory cells has been observed after scaling and/or root planing (SRP) [1]. 


\section{Risk Factors}

DIGE is a multifactorial condition, and its risk factors can be grouped as systemic, genetic, drug, and local $[1,7]$.

\subsection{Systemic Factors}

Seymour et al. suggested that age may be a risk factor for DIGE [26]. DIGE appears to be more pronounced in younger patients [30]. This may be attributed to the increased presence of hormones, such as testosterone and progesterone, in the peri-pubescent age, which are known to have an anabolic effect on gingival fibroblasts [30]. CCB-influenced GE is often observed in patients in the 4th and 5th decades of life [13]. The fact that different drugs are used in patients belonging to different age groups may be reflected in the differing prevalence rates: phenytoin in children, CCBs in middle aged, and cyclosporine across a broader range of age [1]. GE has been reported to be up to three times more prevalent in men than in women [40]. This may be attributed not only to the interaction of greater amount of circulating testosterone with gingival fibroblasts but also to lifestyle and habits. CCBs are typically used to treat hypertension and other cardiovascular diseases; hence pre-existing factors, such as smoking, lifestyle, and diseases, such as DM, obesity, and low-density lipid (LDL), may be considered as risk factors or predisposing factors for DIGE [7].

\subsection{Genetic Factors}

Not all patients receiving CCB treatment develop gingival enlargement. The genetic constitution of an individual may predispose the person to greater risk of DIGE. Gingival enlargement in susceptible individuals may be due to the presence of certain types of fibroblasts having greater genetic predisposition to the drug [1,8]. Different proportions of these subsets of fibroblasts in individuals may result in varying inter-individual responses to CCBs [1]. There are other possible theories of genetic predisposition to CCB-induced GE. CCBs are metabolized by cytochrome P450 enzymes, which are known to have many genetic polymorphs, resulting in variations in metabolism among individuals. This may result in differing serum and tissue concentrations which, aside from lifestyle and oral hygiene practices, could explain the wide spectrum of responses to the drugs $[1,7,8]$.

Pernu et al. suggested a link between individual susceptibility to DIGE and certain major histocompatibility complex (MHC) class II antigens [41], a set of genes that code for proteins on the cell surfaces of dendritic cells, B lymphocytes, and monocytes and are essential for acquired immunity. In humans, the MHC proteins are encoded by the human leukocyte antigen complex (HLA). It has been shown that certain HLA phenotypes (HLAB37, HLA-DR2) in organ transplant recipients taking cyclosporine (CsA) are associated with increased risk for DIGE [14,41]. Interestingly, concomitant use of dihydropyridines (DHPs) with CsA was associated with increase in prevalence and severity of DIGE $[14,41]$.

\subsection{Drug Factors}

The type of drug used plays a role in the occurrence and degree of severity of DIGE. Among the CCBs, isradipine has not been associated with GE. Indeed, one of the treatment modalities is to replace the offending drug with isradipine [1,7,42]. There is conflicting data regarding drug dose as a potential risk factor for DIGE. Ellis et al. reported that the level of nifedipine was 15-316 times in GCF than that found in the plasma, suggesting a direct relation of the pathosis to nifedipine concentration in GCF [43]. Drug concentration in blood and plasma creatine (an indicator of renal function) has been considered risk factors for the severity of DIGE $[14,44]$. On the other hand, Daley et al. reported that there was no relation between severity of GE and dose and serum concentration of cyclosporine [16]. They suggested instead that a minimum drug concentration or threshold was required to be exceeded for the development of GE [16]. CCBs are often used to treat hypertension and reduce the risk of transplant rejection in organ transplant recipients taking cyclosporine $[14,16]$. When taken with cyclosporine, CCBs are known to increase 
GE prevalence, severity, and response to periodontal therapy, especially when nifedipine is used [14,15]. In addition, since CCBs act on cytochrome p450 3A4, an enzyme that is necessary for metabolism of statins prior to its excretion, the ensuing decrease in clearance of the drugs results in an increase in the severity of side effects of the drugs when they are taken concomitantly [7]. Hence, simultaneous use with drugs such as cyclosporin and statins may be considered as risk factors for DIGE. Thomason et al. reported that the duration of the drug treatment was a significant risk factor to severity of DIGE [14]. Indeed, literature suggests that CCB-influenced GE typically begins within the first 3-6 months of starting the medication $[1,7,30,45]$. Taken together, it may be inferred that drug pharmacokinetics play a vital role in the development and progression of DIGE.

\subsection{Local Factors}

Dental plaque is often considered to be essential for the pathogenesis of DIGE $[1,7-9,15,18]$. In a study on beagle dogs that were given nitrendipine, Heijl and Sundín reported the prevalence of GE only in the areas where plaque and gingival inflammation were present [46]. Poor oral hygiene habits indirectly affect the occurrence and manifestation of the condition. Ingenli et al. reported that patients with poor oral hygiene and poor attendance at recall appointments were at greater risk of recurrence of the disease following surgical intervention [47]. Local factors that create limited access for plaque removal, such as malpositioning of teeth, overhanging restorations, ill-fitting prostheses, and presence of calculus, may also be considered risk factors for DIGE [16]. Host response to dental plaque may be exaggerated by its response to the drug and vice versa. For example, CCBs can cause a reduction in salivary flow, which in turn promotes plaque buildup and inflammation and increased risk for GE [48]. Thomason et al. reported that CsA-induced GE was significantly associated with high papilla bleeding index [14]. DIGE does not typically appear in edentulous conditions, which may at least partly be explained by the fact that in the absence of teeth, there is limited nidus to foster plaque. More studies that focus on this peculiar characteristic may shed light on the etiology and resistance to treatment in some patients (Figure 2).

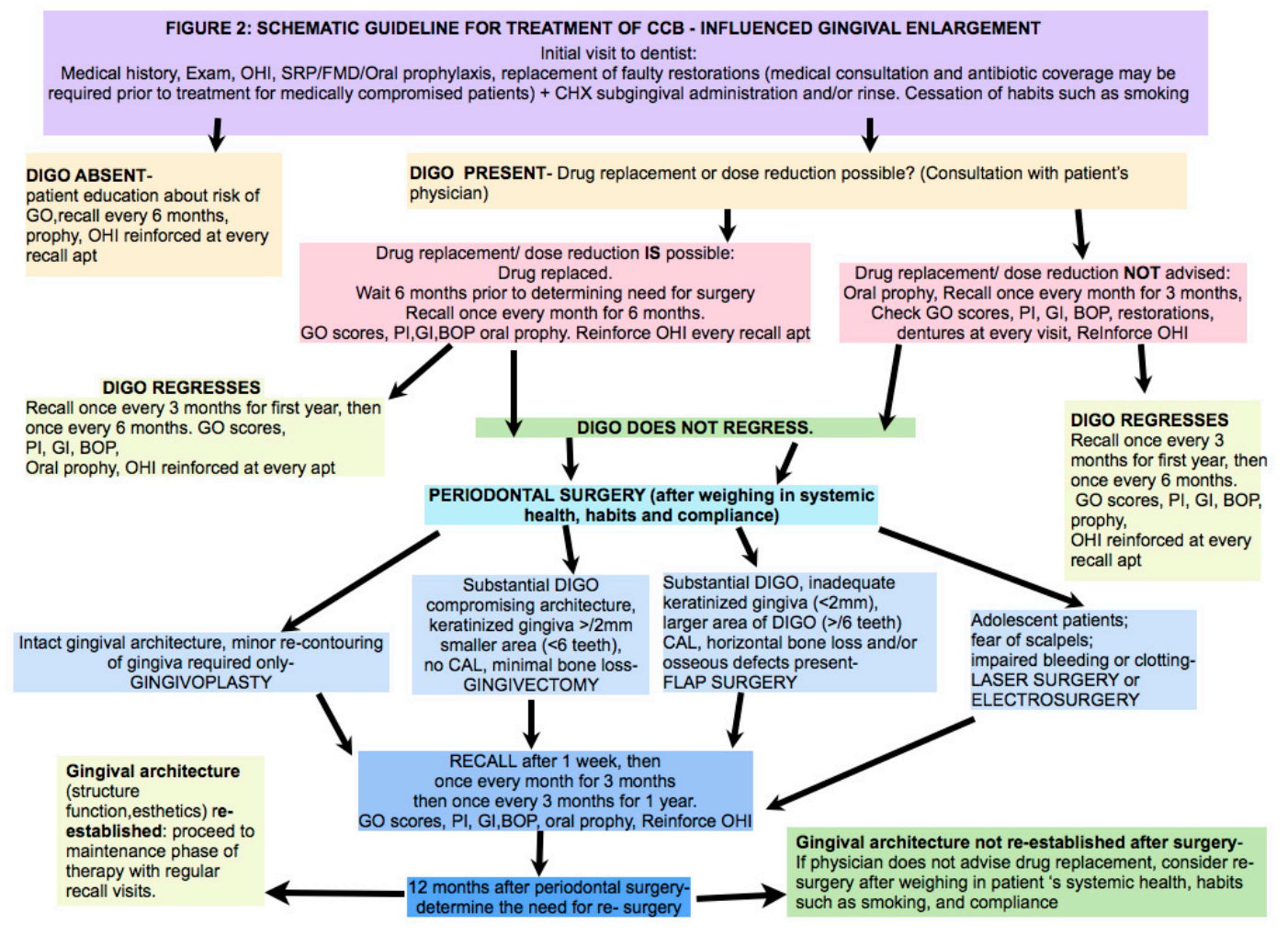

Figure 2. Cont. 
- SRP- Scaling and Root Planing

- $\quad$ FMD- Full Mouth Debridement

- CHX-Chlorhexidine

- DIGO- Drug Influenced Gingival Overgrowth

- CAL- Clinical Attachment Loss

- $\quad$ Gl- Gingival Index

- PI- Plaque Index

- $\quad$ BOP- Bleeding On Probing

- $\quad$ OHI- Oral Hygiene Instructions

- Prophy- Oral Prophylaxis

Figure 2. Schematic Guideline for Treatment of CCB- Influenced Gingival Enlargement.

\section{Treatment}

CCBs are often taken for serious medical conditions and are considered to be life saving drugs. However, to provide holistic care, it is prudent to caution patients of all possible adverse drug reactions (ADRs), including DIGE, prior to starting allopathic therapy. This is especially true for CCBs, since many of these drugs are intended to be taken on a long-term basis, and hence, medical and dental professionals should be aware of this well-known but often overlooked side effect and create an effective treatment strategy.

There are various treatment modalities for drug-induced gingival enlargement; however, they share a common path. Treatment begins from the very first dental visit when, after seeking medical history, the dentist identifies the oral pathosis to be associated with medication. From there on, the dentist and periodontist must work closely with the patient and physician to construct a treatment plan that is customized to the patient's needs, taking into consideration the patient's systemic health, oral hygiene habits, and compliance factors to avoid recurrence.

\subsection{Initial/Non-Surgical Treatment}

Initial treatment should be comprised of meticulous oral hygiene measures, which includes oral hygiene instructions (OHI) and full mouth debridement (FMD) [49] or scaling and root planing (SRP, in the presence of greater probing depths and bone loss) in multiple sessions. Dental conditions that cause a nidus for bacterial growth, such as faulty restorations and ill-fitting dentures, should be replaced, and teeth with severe clinical attachment loss must be extracted to ameliorate patient discomfort. In the presence of debilitating health conditions, consultation with the attending physician prior to treatment is required. Hancock and Swan reported a marked regression by SRP [50]. Dannewitz et al. applied the FMD concept as described by Quirynen [51] in a group of 11 patients with CCB- or cyclosporine-influenced GE [49]. Sub gingival debridement was performed by scaling and root planing of all teeth under local anesthesia within $24 \mathrm{~h}$ [49]. Those taking cyclosporine were pre-medicated with antibiotics due to increased risk of infection from immune suppression [49].

Chlorhexidine was placed sub gingivally in the pockets in all patients and was used as a rinse after the procedure and post visit daily for two weeks [49]. A reduction in all clinical parameters, including GE, probing depths, and gingival bleeding, was noted at two and four months [49]. Following FMD and regular supportive periodontal treatment programs specific for each patient, the need for periodontal surgery was reduced to three patients [49]. Furthermore, no recurrence was noted during recall after 28 months [49]. 
Hence, plaque-control measures are important not only in the initial phase but also in the maintenance phase [47,49].

Cessation of the offending drug and / or substitution with another is the ideal treatment option that has been found to be effective in reducing GE $[1,7,45]$. Since halting CCB therapy may not be systemically beneficial in the long term for some patients, substitution with a drug that provides similar cardiovascular benefits with fewer side effects may be an effective initial treatment option. Studies report an improvement in gingival health following a switch to a drug that does not cause GE [18,22,42]. This is often combined with a stringent plaque removal regime [18,22,42]. Westbrook reported a reduction in gingival overgrowth and probing depths after 12 weeks of substituting nifedipine with isradipine, a third-generation CCB of the same class, without causing significant change in systemic blood pressure [42]. The reduced probing depth was attributed to the reduction in the inflammation by scaling and root planing at baseline and recession of the gingival margins [42]. Similarly, other antihypertensive drugs, such as angiotensin converting enzyme (ACE) inhibitorslike captopril and moxonidine, an alpha 2 /imadazoline receptor agonist, which acts on the central nervous system and inhibits the sympathetic nervous system, have been used as substitutes $[1,18]$. This strategy of changing the drug regime has been reported to be effective in other forms of DIGE as well: tacrolimus has been used as an alternative to cyclosporine in organ transplant recipients; carbamazepine is used to replace phenytoin in the management of epilepsy [1,7]. Only the physician can make pharmacologic decisions after weighing the benefits versus the risk. Studies have reported an improvement in clinical parameters of phenytoin-influenced DIGO with the use of topical and systemic folic acid (FA), although greater efficacy has been reported with the use of topical than systemic FA [9]. The regression of GO after use of FA may be explained by the theory that when active transport of FA into the cell is inhibited, presence of high concentration of FA in the GCF recreates a concentration gradient and resumes FA cellular uptake [9]. Whether this strategy can be used as a therapeutic measure in CCB and other DIGE needs to be further explored. Systemic use of NSAIDs that control inflammation, androgen receptor inhibitors that block collagen production via the androgen receptordependent CTGF/CCN2-collagen cascade, azithromycin, and topical use of anti-fungal drugs to alleviate symptoms have also been suggested [1,9].

Literature on the combination of various non-surgical treatment strategies is contradictory. Some studies have reported a complete regression of DIGE by SRP alone without the need for drug replacement $[49,50,52]$, whereas Westbrook et al. reported that without the switch from nifedipine to isradipine, oral hygiene measures were not effective [42]. Although the strategy of drug replacement by itself may be successful, a treatment plan consisting of FMD or SRP and OHI has been found to have more predictable results with less chance of recurrence $[25,42,47,48]$. When pharmacotherapy is modulated to improve gingival and oral health, it is advisable to wait for at least six months following the change in the drug before determining the need for surgical intervention [1].

Regression is usually seen in four weeks following drug replacement with adequate plaque control [24]. Long-term results with complete regression following initial phase of treatment have been reported [49,51]. In some studies, however, it has been reported that even aggressive plaque control measures and/or drug replacement therapy without surgical intervention may be insufficient for complete resolution of GE [42].

\subsection{Surgical Treatment}

When oral hygiene and pharmacotherapeutic measures are unsuccessful in complete resolution of DIGE, periodontal surgery is necessary to reestablish gingival architecture and restore function and esthetics. It is important to reiterate that surgical phase should not be attempted prior to the hygienic phase for several reasons. First, professional oral hygiene care is necessary to alleviate some of the symptoms caused by bacterial plaque. Second, following plaque control measures, the subsidence of inflammation will make surgical correction easier and more predictable. Third, complete resolution of the condition 
may be observed after plaque control and drug modulation, which obviates the need for surgery $[49,50,52]$. In some patients on CCB medication, invasive treatment may be contraindicated. The patient's systemic health must be considered, and consultation with the physician prior to performing periodontal surgery is necessary. The surgical technique employed is dependent on periodontal condition and clinical presentation of the condition; at times, different therapeutic modes may be employed at different sites in the oral cavity of the same patient [45]. Often, $0.12 \%$ Chlorhexidine gluconate is used during and after periodontal surgery to promote healing [45]. Gingivectomy is undertaken to remove excess keratinized tissue. The procedure as described by Glickman [53] employs a scalloped external bevel incision using Kirkland's knife or 15 BP blade [45]. Gingivoplasty is done in areas where only minor modifications of gingival contour are necessary [32]. Gingivectomy re-establishes the gingival architecture and creates a smoother contour than flap procedures [53]. Although healing is by secondary intention, it is considered the gold standard for surgery for GE [54]. Periodontal flap surgery is performed in lieu of gingivectomy when there is presence of inadequate keratinized tissue, osseous defects, and/or clinical attachment loss (CAL) or when large areas are involved ( $\geq 6$ teeth) [32]. Periodontal flap surgery is performed to remove inflamed connective tissue, reduce pocket depths, and correct osseous defects [1,32]. Modified Widman flap [29], flap with 90-degree incision [32,47], and apically positioned flap procedure are commonly performed [45]. Following flap surgery, the wound heals by primary intention [45].

Lasers may be used to remove excess gingival tissue. Use of Nd:Yag with $1065 \mathrm{~nm}$ wavelength, diode laser with $810 \mathrm{~nm}$ wavelength and $\mathrm{CO}_{2}$ laser with $10,600 \mathrm{~nm}$ wavelength has been described [1,54]. Laser surgery has the advantage of a relatively dry field during the procedure and less hemorrhage and discomfort postoperatively [54] as compared to gingivectomy and flap procedures. High-energy lasers inhibit collagen production and result in the formation of slough or scab that protects the underlying tissue [54]. Electrosurgery has also been used for surgical correction of DIGE. It is especially useful in adolescent patients, patients with mental disabilities, or impaired bleeding or clotting mechanisms when conventional modes for surgery are contraindicated [1].

In a study by Pilloni et al., probing depths were found to be reduced following flap surgery as compared to gingivectomy at 6 and 12 months [45]. The authors suggested that this was due to the extensive open wound that was created following gingivectomy as compared to the thin incision line resulting from flap surgery [45]. Furthermore, the healing pattern is different following the two procedures, with the healing beginning from within connective tissue in the flap procedure resulting in slower clinical manifestation of GE [45]. Conflictingly, in a split mouth study, Mavrogiannis et al. reported no difference in rate of recurrence of DIGE between gingivectomy and flap procedure after six months [54]. However, when compared with laser excision, there was greater recurrence of GE following conventional gingivectomy [54]. Similar to flap surgery, mitotic activity begins from within connective tissue following laser surgery; hence, more time may be required for clinical manifestation of recurrence [54]. From the data above, it can be deduced that the surgical technique employed has an impact in the clinical outcome of treatment.

\subsection{Maintenance and Recurrence}

A supportive periodontal maintenance program with regular recall appointments for follow up is recommended following active periodontal therapy to monitor oral health, reinforce home care instructions, and perform in-office plaque control measures. Ilgenli reported $43 \%$ recurrence 18 months after periodontal therapy in nifedipine-associated GE and overall $34 \%$ recurrence of GO in patients who were on cyclosporine or nifedipine [47]. Poor attendance at recall appointments was associated with increased risk of recurrence [47]. A significant association was found between gingival inflammation detected at 18 months and recurrence [47]. An inverse correlation of recurrence with age of the patient was also observed [47]. Pernu et al. reported that 13 of the 27 renal transplant patients on CsA showed recurrence 15 months following periodontal therapy [15]. It must be noted that in 
this study, supportive periodontal maintenance therapy was not provided after surgery, and this may explain the higher recurrence rate of GE than in the Ilgenli study [15,47]. On the other hand, in a more recent study, it was observed that $47.2 \%$ of patients using CCB who underwent periodontal treatment experienced recurrence in spite of undergoing supportive periodontal maintenance [55]. Recurrence can be seen within six months of periodontal surgery $[45,54]$; however, in general, the results of surgery are said to be maintained for an average of 12 months after surgery [1]. The diversity in recurrence rates among different drugs and factors associated with recurrence warrants further investigation.

Figure 2 illustrates a treatment strategy for minimizing recurrence of GO.

\section{Conclusions}

When enlargement of an organ occurs due to an increase in the number of cells, the condition is referred to as hyperplasia, whereas when enlargement occurs due to increase in the size of the cells, it is referred to as hypertrophy. What was termed as drug-induced gingival hyperplasia is now known as drug-influenced gingival enlargement, categorized under "dental biofilm induced gingivitis" in the most recent classification scheme for periodontal diseases [33]. This change in terminology reflects an evolution in understanding of the pathogenesis and development of DIGE. Whereas earlier studies focused on the theory that DIGE is caused by an increase in connective tissue elements, more recent studies suggest that it is a result of an imbalance between catabolic and anabolic mechanisms that are necessary for regulating the periodontium [9]. Historically, the pathogenesis of DIGE has been described as being caused by inflammatory and noninflammatory mechanisms; however, they are not distinct or separate; rather, the pathways appear to be confluent in various steps of the disease. In addition, there is insurmountable evidence that dental plaque is necessary for the development and progress of the condition and that the offending drug mainly alters the response of the periodontium to plaque bacteria. It is also important to remember that plaque-induced gingival inflammation does not only contribute to the occurrence of DIGE but is also a consequence of it due to limited access for oral hygiene.

The literature involving pathogenesis of CCB-influenced GE, treament, and clinical outcome of various treatment modalities is conflicting. Nevertheless, the subject is of great relevance due to the widespread use of the drugs that cause it, the pervasiveness of the systemic diseases that require their use, and the functional and cosmetic implications of DIGE. Within the limitation of this article, it may be inferred that genetic makeup, plaqueinduced gingival inflammation, type of drug used, duration of drug use, lifestyle and oral hygiene habits, treatment modalities utilized, and patient compliance are important prognostic factors that affect the prevalence and severity of the condition, long-term clinical outcome, and risk of recurrence following periodontal treatment. More studies that focus on predisposing factors should be undertaken that will aid in identifying individuals who are at greater risk for developing DIGE. Patients taking these drugs must be forewarned about this side effect so that they take adequate oral hygiene measures that will help prevent or at least minimize the condition. Longitudinal studies on causes of recurrence will help shed light on why periodontal therapy is successful in some patients, whereas in others, there is recrudescence of gingival enlargement.

Author Contributions: Both authors (P.T. and V.T.) have equal contribution in conceptualization, methodology, software, validation, formal analysis, reading resources, original draft preparation, writing review and editing. Both authors have read and agreed to the published version of the manuscript.

Funding: This research did not receive any grant from funding agencies in the public, commercial, or not for profit sectors.

Institutional Review Board Statement: Not applicable.

Informed Consent Statement: Not applicable.

Data Availability Statement: Additional/supporting data in this review is available on request. 
Conflicts of Interest: The authors declare no conflict of interest.

\section{References}

1. Bharti, V.; Bansal, C. Drug-induced gingival overgrowth: The nemesis of gingiva unravelled. J. Indian Soc. Periodontol. 2013, 17, 182-187. [CrossRef]

2. Hatahira, H.; Abe, J.; Hane, Y.; Matsui, T.; Sasaoka, S.; Motooka, Y.; Hasegawa, S.; Fukuda, A.; Naganuma, M.; Ohmori, T.; et al. Drug-induced gingival hyperplasia: A retrospective study using spontaneous reporting system databases. J. Pharm. Health Care Sci. 2017, 3, 1-11. [CrossRef] [PubMed]

3. Prachi, S.; Jitender, S.; Rahul, C.; Jitendra, K.; Priyanka, M.; Disha, S. Impact of oral contraceptives on periodontal health. Afr. Health Sci. 2019, 19, 1795-1800. [CrossRef] [PubMed]

4. McKeever, R.G.; Hamilton, R.J. Calcium Channel Blockers. 2019. Available online: https://www.ncbi.nlm.nih.gov/books/NBK4 82473 / (accessed on 1 July 2021).

5. Bloch, M.J.; Basile, J. Major Side Effects and Safety of Calcium Channel Blockers. 2019. Available online: https:/ /www.uptodate. com/contents/major-sideeffects-and-safety-of-calciumchannel-blockers (accessed on 1 July 2021).

6. Kimball, O.P. The treatment of epilepsy with sodium diphenyl hydantoinate. JAMA 1939, 112, 1244-1245. [CrossRef]

7. Pasupuleti, M.K.; Musalaiah, S.V.; Nagasree, M.; Kumar, P.A. Combination of inflammatory and amlodipine induced gingival overgrowth in a patient with cardiovascular disease. Avicenna J. Med. 2013, 3, 68-72. [CrossRef] [PubMed]

8. Ganesh, P.R. Immunoexpression of interleukin-6 in drug-induced gingival overgrowth patients. Contemp. Clin. Dent. 2016, 7, 140-145. [CrossRef]

9. Brown, R.S.; Arany, P. Mechanism of drug-induced gingival overgrowth revisited: A unifying hypothesis. Oral Dis. 2014, 21, e51-e61. [CrossRef]

10. Ramon, Y.; Behar, S.; Kishon, Y.; Engelberg, I.S. Gingival hyperplasia caused by nifedipine-A preliminary report. Int. J. Cardiol. 1984, 5, 195-204. [CrossRef]

11. Lederman, D.; Lumerman, H.; Reuben, S.; Freedman, P.D. Gingival hyperplasia associated with nifedipine therapy. Oral Surg. Oral Med. Oral Pathol. 1984, 57, 620-622. [CrossRef]

12. Seymour, R.A.; Ellis, J.; Thomason, J.M.; Monkman, S.; Idle, J.R. Amlodipine-induced gingival overgrowth. J. Clin. Periodontol. 1994, 21, 281-283. [CrossRef] [PubMed]

13. Gaur, S.; Agnihotri, R. Is dental plaque the only etiological factor in Amlodipine induced gingival overgrowth? A systematic review of evidence. J. Clin. Exp. Dent. 2018, 10, e610-e619. [CrossRef] [PubMed]

14. Thomason, J.M.; Seymour, R.A.; Ellis, J.S.; Kelly, P.J.; Parry, G.; Dark, J.; Wilkinson, R.J.; Ilde, J.R. Determinants of gingival overgrowth severity in organ transplant patients. An examination of the role of HLA phenotype. J. Clin. Periodontol. 1996, 23, 628-634. [CrossRef]

15. Pernu, H.E.; Pernu, L.M.H.; Knuuttila, M.L. Effect of periodontal treatment on gingival overgrowth among Cyclosproine A treated renal transplant recipients. J. Periodontol. 1993, 64, 1098-1100. [CrossRef] [PubMed]

16. Daley, T.D.; Wysocki, G.P. Cyclosporine Therapy: Its Significance to the Periodontist. J. Periodontol. 1984, 55, 708-712. [CrossRef]

17. Tahamtan, S.; Shirban, F.; Bagherniya, M.; Johnston, T.P.; Sahebkar, A. The effects of statins on dental and oral health: A review of preclinical and clinical studies. J. Transl. Med. 2020, 18, 1-42. [CrossRef]

18. Khzam, N.; Bailey, D.; Yie, H.S.; Bakr, M.M. Gingival Enlargement Induced by Felodipine Resolves with a Conventional Periodontal Treatment and Drug Modification. Case Rep. Dent. 2016, 2016, 1-6. [CrossRef] [PubMed]

19. Nyska, A.; Shemesh, M.; Tal, H.; Dayan, D. Gingival hyperplasia induced by calcium channel blockers: Mode of action. Med. Hypotheses 1994, 43, 115-118. [CrossRef]

20. Sooriyamoorthy, M.; Gower, D.B.; Eley, B.M. Androgen metabolism in gingival hyperplasia induced by nifedipine and cyclosporin. J. Periodontal. Res. 1990, 25, 25-30. [CrossRef]

21. Nishikawa, S.; Tada, H.; Hamasaki, A.; Kasahara, S.; Kido, J.-I.; Nagata, T.; Ishida, H.; Wakano, Y. Nifedipine-Induced Gingival Hyperplasia: A Clinical and In Vitro Study. J. Periodontol. 1991, 62, 30-35. [CrossRef]

22. Aldemir, N.M.; Begenik, H.; Emre, H.; Erdur, F.M.; Soyoral, Y. Amlodipine-induced gingival hyperplasia in chronic renal failure: A case report. Afr. Heal. Sci. 2013, 12, 576-578. [CrossRef]

23. Subramani, T.; Rathnavelu, V.; Alitheen, N.B. The Possible Potential Therapeutic Targets for Drug Induced Gingival Overgrowth. Mediat. Inflamm. 2013, 2013, 1-9. [CrossRef]

24. Kasasa, S.; Soory, M. The effect of interleukin-1 (IL-1) on androgen metabolism in human gingival tissue (HGT) and periodontal ligament (PDL). J. Clin. Periodontol. 1996, 23, 419-424. [CrossRef]

25. Ramírez-Rámiz, A.; Brunet-Llobet, L.; Lahor-Soler, E.; Miranda-Rius, J. On the Cellular and Molecular Mechanisms of DrugInduced Gingival Overgrowth. Open Dent. J. 2017, 11, 420-435. [CrossRef] [PubMed]

26. Seymour, R.A.; Ellis, J.S.; Thomason, J.M. Risk factors for induced gingival over growth. J. Clin. Periodontol. 2000, 27, $217-223$. [CrossRef] [PubMed]

27. Thomason, J.M.; Ellis, J.S.; Jovanovski, V.; Corson, M.; Lynch, E.; Seymour, R.A. Analysis of changes in gingival contour from three-dimensional co-ordinate data insubjects with drug-induced gingival overgrowth. J. Clin. Periodontol. 2005, 32, 1069-1075. [CrossRef] 
28. Tejnani, A.; Gandevivala, A.; Bhanushali, D.; Gourkhede, S. Combined treatment for a combined enlargement. J. Indian Soc. Periodontol. 2014, 18, 516-519. [CrossRef]

29. Ikawa, K.; Ikawa, M.; Shimauchi, H.; Iwakura, M.; Sakamot, S. Treatment of gingival overgrowth induced by Manidipine administration. A case report. J. Periodontol. 2002, 73, 115-122. [CrossRef] [PubMed]

30. Samudrala, P.; Chava, V.K.; Chandana, T.S.; Suresh, R. Drug-induced gingival overgrowth: A critical insight into case reports from over two decades. J. Indian Soc. Periodontol. 2016, 20, 496-502. [CrossRef] [PubMed]

31. Lafzi, A.; Farahani, R.M.; Shoja, M.A. Amlodipine-induced gingival hyperplasia. Med. Oral Patol. Oral Cir. Bucal. 2006, 11, E480-E482. [PubMed]

32. Newman, M.G.; Takei, H.; Klokkevold, P.R.; Carranza, F.A. Carranza's Clinical Periodontology, 10th ed.; Elsevier: St. Louis, MO, USA, 2006; pp. 747-754, 1766-1772.

33. Caton, J.G.; Armitage, G.; Berglundh, T.; Chapple, I.L.; Jepsen, S.; Kornman, K.S.; Mealey, B.L.; Papapanou, P.N.; Sanz, M.; Tonetti, M.S. A new classification scheme for periodontal and peri-implant diseases and conditions-Introduction and key changes from the 1999 classification. J. Clin. Periodontol. 2018, 45, S1-S8. [CrossRef]

34. Seymour, R.A.; Smith, D.G.; Turnbull, D.N. The effects of phenytoin and sodium valproate on the periodontal health of adult epileptic patients. J. Clin. Periodontol. 1985, 12, 413-419. [CrossRef]

35. Ellis, J.S.; Seymour, R.A.; Robertson, P.; Butler, T.J.; Thomason, J.M. Photographic scoring of gingival overgrowth. J. Clin. Periodontol. 2001, 28, 81-85. [CrossRef]

36. Quach, H.; Ray-Chaudhuri, A. Calcium channel blocker induced gingival enlargement following implant placement in a fibula free flap reconstruction of the mandible: A case report. Int. J. Implant. Dent. 2020, 6, 1-5. [CrossRef] [PubMed]

37. Asif, S.M.; Shaik, N.; Barthunia, B.; Kaleem, S.M.; Zakirulla, M.; Kota, M.Z.; Baig, F.A.H. Nifedipine induced gingival enlargement in an edentulous patient: A case report with one year follow up. BMC Oral Health 2018, 18, 227. [CrossRef] [PubMed]

38. Lin, K.; Guilhoto, L.M.; Yacubian, E.M.T. Drug-induced gingival enlargement-part II. Antiepileptic drugs: Not only phenytoin is involved. J. Epilepsy Clin. Neurophysiol. 2007, 13, 83-88. [CrossRef]

39. Joshi, S.; Bansal, S. A Rare Case Report of Amlodipine-Induced Gingival Enlargement and Review of Its Pathogenesis. Case Rep. Dent. 2013, 2013, 138248. [CrossRef]

40. Ellis, J.S.; Seymour, R.A.; Steele, J.G.; Robertson, P.; Butler, T.J.; Mark, J. ThomasonPrevalence of gingival overgrowth induced by calcium channel blockers: A community-based study. J. Periodontol. 1999, 70, 63-67. [CrossRef]

41. Pernu, H.E.; Knuttilla, M.L.E.; Hutternen, K.R.H.; Tiilikainen, A.S.K. Drug Induced gingival overgrowth and class II major histocompatibilty antigens. Transplantation 1994, 57, 1811-1813.

42. Westbrook, P.; Bednarczyk, E.M.; Carlson, M.; Sheehan, H.; Bissada, N.F. Regression of Nifedipine-Induced Gingival Hyperplasia Following Switch to a Same Class Calcium Channel Blocker, Isradipine. J. Periodontol. 1997, 68, 645-650. [CrossRef]

43. Ellis, J.; Monkman, S.; Seymour, R.; Idle, J. Determination of nifedipine in gingival crevicular fluid: A capillary gas chromatographic method for nifedipine in microlitre volumes of biological fluid. J. Chromatogr. B Biomed. Sci. Appl. 1993, 621, 95-101. [CrossRef]

44. Seymour, R.A.; Smith, D.G.; Rogers, S.R. The comparative effect of Azothriopine and Cyclosporine on some gingival health parameters of renal transplant patients. J. Clin. Periodontol. 1987, 14, 311-314. [CrossRef] [PubMed]

45. Pilloni, A.; Camargo, P.M.; Carere, M.; Carranza, F.A. Surgical Treatment of Cyclosporine A- and Nifedipine-Induced Gingival Enlargement: Gingivectomy Versus Periodontal Flap. J. Periodontol. 1998, 69, 791-797. [CrossRef] [PubMed]

46. Heijl, L.; Sundin, Y. Nitrendipine-Induced Gingival Overgrowth in Dogs. J. Periodontol. 1989, 60, 104-112. [CrossRef]

47. Ilgenli, T.; Atilla, G.; Baylas, H. Effectiveness of Periodontal Therapy in Patients with Drug-Induced Gingival Overgrowth. Long-Term Results. J. Periodontol. 1999, 70, 967-972. [CrossRef]

48. Gopal, S.; Joseph, R.; Santhosh, V.C.; Kumar, V.V.; Joseph, S.; Shete, A.R. Prevalence of gingival overgrowth induced by antihypertensive drugs: A hospital-based study. J. Indian Soc. Periodontol. 2015, 19, 308-311. [CrossRef] [PubMed]

49. Dannewitz, B.; Krieger, J.K.; Simon, I.; Dreyhaupt, J.; Staehle, H.J.; Eickholz, P. Full-mouth disinfection as a nonsurgical treatment approach for drug-induced gingival overgrowth: A series of 11 cases. Int. J. Periodontics Restor. Dent. 2010, 30, 63-71.

50. Hancock, R.H.; Swan, R.H. Nifedipine-induced gingival overgrowth. J. Clin. Periodontol. 1992, 19, 12-14. [CrossRef] [PubMed]

51. Quirynen, M.; De Soete, M.; Boschmans, G.; Pauwels, M.; Coucke, W.; Teughels, W.; Van Steenberghe, D. Benefit of "one-stage full-mouth disinfection" is explained by disinfection and root planing within 24 hours: A randomized controlled trial. J. Clin. Periodontol. 2006, 33, 639-647. [CrossRef]

52. Devanoorkar, A.; Guttiganur, N. Interdisciplinary approach in the management of medically compromised patient with drug induced gingival enlargement. J. Interdiscip. Med. 2019, 9, 44-47. [CrossRef]

53. Glickman, I. Hyperplasia of the gingiva associated with dilantin therapy. J. Am. Dent. Assoc. 1941, 28, 199-207. [CrossRef]

54. Mavrogiannis, M.; Ellis, J.; Seymour, R.A.; Thomason, J.M. The efficacy of three different surgical techniques in the management of drug-induced gingival overgrowth. J. Clin. Periodontol. 2006, 33, 677-682. [CrossRef] [PubMed]

55. Fardal, $\varnothing$.; Lygre, H. Management of periodontal disease in patients using calcium channel blockers -gingival overgrowth, prescribed medications, treatment responses and added treatment costs. J. Clin. Periodontol. 2015, 42, 640-646. [CrossRef] [PubMed] 